This is a non-final version of an article published in final form in "Bandlitz, S., Purslow, C., Murphy, P. J., Pult, H., \& Bron, A. J. (2014). A New Portable Digital Meniscometer: Optometry and Vision Science, 91(1), e1-e8. https://doi.org/10.1097/OPX.0000000000000062

Title:

\title{
A new portable digital meniscometer
}

Authors:

Stefan Bandlitz MS, MCOptom

Christine Purslow PhD, MCOptom

Paul J Murphy PhD, FAAO

Heiko Pult PhD, FAAO

Anthony J Bron MD

School of Optometry and Vision Sciences, Cardiff University, Cardiff, Wales, United Kingdom (SB, PJM, HP), and Cologne School of Optometry, Cologne, Germany (SB), and School of Health Professions, Plymouth, United Kingdom (CP), and Dr Heiko Pult - Optometry and Vision Research, Weinheim, Germany (HP) and Nuffield Laboratory of Ophthalmology, University of Oxford, Oxford, UK (AJB)

Tables and Figures: 10 Figures (9: a,b)

$\underline{\text { Wordcount: }}$

\section{Corresponding Author}

Stefan Bandlitz

Cologne School of Optometry (HFAK)

Bayenthalguertel 6-8

D-50968 Koeln

Germany

e-mail: bandlitz@hfak.de; Telephone: 0049-221-348080 


\section{Abstract}

Purpose: The aim of this study was (i) to develop a new portable, slit-lamp mounted digital meniscometer (PDM), and (ii) to test its accuracy and repeatability compared to the available Yokoi et al video-meniscometer (VM). ${ }^{1}$

Methods: The medians of three consecutive measurements on 5 glass capillaries (internal radii 0.100 to $0.505 \mathrm{~mm}$ ) were compared between VM and PDM at two different sessions. Also, the central lower tear meniscus radius (TMR) in 20 normal subjects (10M, 10F; mean age $32.3 \mathrm{SD} \pm 9.3$ years) was measured using both techniques. Correlations between the instruments were analyzed using the Pearson coefficient. Differences between sessions and instruments were analyzed using Bland-Altman plots, coefficient of repeatability (CR) and paired t-tests.

Results: The PDM and VM were accurate in vitro (95\% Cl of difference: PDM $0.0134 \mathrm{~mm}$ to $+0.0074 ; p=0.468 ; \mathrm{VM}-0.0282$ to $+0.0226 ; p=0.775)$, and reproducible between sessions (95\% CR: 0.019 and 0.018, respectively). The mean difference between the PDM and VM in vitro was $0.0002 \mathrm{~mm}(\mathrm{Cl}-0.0252$ to + 0.0256; $p=0.984)$. In human subjects, TMR measured with the PDM $(0.34 \pm 0.10$ $\mathrm{mm})$ and VM $(0.36 \pm 0.11)$ was significantly correlated $(r=0.940 ; p<0.001)$, and there was no statistically significant difference between the measured TMR of the instruments $(p=0.124)$.

Conclusions: This new slit-lamp mounted digital meniscometer produces accurate and reliable measurements, and provides similar values for tear meniscus radius, in human studies, to the existing video-meniscometer. The instrument is suitable for use in both research and clinical practice. 
Key words: Portable digital meniscometer, reflective meniscometry, tear meniscus radius, tear film, dry eye diagnosis 
1 Dry eye is a multi-factorial disease resulting in damage to the ocular surface and

2 patient symptoms of discomfort, principally due to an insufficient tear film. ${ }^{2}$ This

3 insufficiency is typically caused by an aqueous deficiency or increased evaporation of

4 the tear film. ${ }^{2}$ The tear menisci along the superior and inferior lid margins represent

575 to $90 \%$ of the tear film volume at the ocular surface. ${ }^{3}$ Thus, evaluation of the tear

6 menisci is regarded as an indicator of the tear film volume and is important in the

7 diagnosis of aqueous tear deficiency. ${ }^{4-7}$ Measurement of the tear meniscus height is

8 used in many studies for tear volume assessment and, in clinical practice, it is mostly

9 performed with a slit-lamp. ${ }^{8-13}$ However, identifying the upper limit of the meniscus at

the slit lamp is challenging unless sodium fluorescein is added to the tear film,

11 rendering the test invasive and less informative.

In contrast, the analysis of the radius of curvature of the tear meniscus (TMR), while

more difficult to do, is assumed to be better in predicting tear volume in a non-

invasive way. ${ }^{1,6,14-16}$ TMR can be evaluated by the use of an optical coherence

tomographer, ${ }^{5,15,17-20}$ or a meniscometer., 14, 21-24 Although both instruments measure

the tear meniscus non-invasively, they have not found wide application among

clinicians, either because they are not commercially available in all parts of the world,

or they are too expensive. ${ }^{25}$ One such meniscometer, developed by Yokoi et al,

projects a defined grid of black and white lines onto the tear meniscus. ${ }^{1,26}$ The

meniscus acts as a concave mirror and the size of the reflected image is used to

calculate TMR. However, to our knowledge, only three such video-meniscometers

are in use worldwide. Consequently, the aim of this study was (i) to develop a new

portable, slit-lamp mounted meniscometer, and (ii) to test its accuracy and

repeatability compared to the available Yokoi et al video-meniscometer. 


\section{Methods}

Instrument development:

To project a target onto the anterior curvature of the tear meniscus, an illuminated target was needed. A conventional iPod-touch (Apple Inc., Cupertino, CA, USA) with a 3.5" multi-touch-display $7.5 \times 5.0 \mathrm{~cm}$ (480 x 320 Pixel) was used for this purpose. An application software for the iPod-touch was developed to generate a grid of black and white lines on the display (Figure 1). The width of the lines is shown on the display and can be varied between 0.15 and $7.5 \mathrm{~mm}$ via the touch screen.

Additionally, the vertical orientation of the iPod is given in degrees on the display. To define the distance from the tear meniscus, the iPod-touch was fixed to a digital photo slit-lamp (BQ900 with IM900 digital imaging module, Haag-Streit, Koeniz, Switzerland). A commercially available iPod-Touch stand (Xtand, Just Mobile e.K., Berlin, Germany) was modified and mounted on a metal axis on the stand so that it could be fixed to the tonometer post of the slit-lamp (Figure 2). This set-up allowed adjustment of the target in several different orientations in relation to the tear meniscus.

Specular reflection with the slit-lamp was achieved by setting the incidence angle of the target grid equal to the observation angle of the microscope, which was set at 40x magnification. The distance between the target (iPod) and the tear meniscus (a=target distance) was controlled with a sliding calliper.

Imaging of the reflection was produced through a digital camera (RM 01 CCDcamera, 1600 x 1200 pixel, Haag-Streit, Koeniz, Switzerland) incorporated into the slit-lamp, and relayed to image-grabbing software (EyeSuite Imaging, Haag-Streit, 
51 Koeniz, Switzerland) within a PC. The computer screen had a resolution of $1280 \mathrm{x}$

52 1024, producing a total magnification of about 100x, which was the best compromise

53 in terms of resolution and brightness of the image. On the image of the reflected grid

54 obtained, the distance between the outer edges of two white lines (total wide of two

55 white and one black projected line) was measured using the Image 1.46 software

56 (http://rsbweb.nih.gov/ij) (Figure 3). With a known size of the target (y), distance of

57 the target (a) and the size of the image on the screen ( $\left.y^{\prime}\right)$, the radius of the tear

58 meniscus can be calculated using the given formula for a concave mirror (Figure 4).

59 In vitro study:

60 The inner surfaces of 5 glass capillaries were used as a model of the tear meniscus

61 The inner diameters of the glass capillaries (Hilgenberg $\mathrm{GmbH}$, Malsfeld, Germany)

62 were confirmed by use of a hole-gauge before cutting them in half. The medians of

63 three consecutive measurements on the 5 glass capillaries (radii $0.100 \mathrm{~mm}$ to

$640.505 \mathrm{~mm}$ ) were compared between the existing video-meniscometer (VM) (Figure 5)

65 and the new portable digital meniscometer (PDM) at two different sessions and after

66 re-set-up of the PDM.

67 In vivo study:

68 Twenty subjects ( male $=10$, female $=10$, mean age 32.3 years, range $=23-56$

69 years) were randomly selected from the students and staff of the School of

70 Optometry and Vision Sciences at Cardiff University, UK. All procedures obtained the

71 approval of the Cardiff School of Optometry and Vision Sciences Human Ethics

72 Committee and were conducted in accordance with the requirements of the

73 Declaration of Helsinki. All subjects gave written informed consent before 74 participating in the study. 
Subjects were excluded if they were pregnant or breastfeeding; had a current or previous condition known to affect the ocular surface or tear film; had a history of previous ocular surgery, including refractive surgery, eyelid tattooing, eyelid surgery, or corneal surgery; had any previous ocular trauma, were diabetic, were taking medication known to affect the ocular surface and/or tear film, and/or had worn contact lenses less than two weeks prior to the study. Exclusion criteria was dry eye, defined by either an item-weighted McMonnies questionnaire score $>14.5$ or a fluorescein tear break-up time $<10$ seconds.

The lower TMR was measured by one observer using both techniques (VM and PDM) in a randomized order. The median of three consecutive measurements was recorded for both techniques. All assessments were of the inferior tear meniscus of the right eye directly below the pupil centre with the subject looking straight ahead at a fixation target. The room temperature and relative humidity were controlled to remain within normal limits. To minimize diurnal and inter- blink variation, measurements were taken in the morning between 10 and 12 o'clock and 3 to 4 seconds after a blink.

\section{Statistical analyses:}

Normal distribution of data was analysed by Shapiro-Wilk test. Differences between sessions (day 1 and day 2) and instruments were analyzed using Bland- Altman plots, coefficient of repeatability (CR) and paired t-tests. The relationship between PDM and VM measurements was analyzed by Pearson product moment correlation. The data were analyzed by use of SigmaPlot 12 (Systat Software Inc., Chicago, USA) and BiAS 10 (epsilon-Verlag, Darmstadt, Germany). 


\section{Results}

101

102

103

104

105

106

107

108

109

110

111

112

113

114

115

116

117

118

119

120

121

122

123

124

In vitro study:

The PDM and VM were accurate (95\% CI: PDM -0.0134 to +0.0074mm; $p=0.468$;

VM -0.0282 to $+0.0226 m m ; p=0.775)$, and reproducible between sessions $(95 \% \mathrm{CR}$ :

$0.019 \mathrm{~mm}$ and $0.018 \mathrm{~mm}$, respectively) (Fig. 5.6). The mean difference between the PDM and VM was 0.0002mm ( $\mathrm{Cl}-0.0252$ to +0.0256mm; $\mathrm{p}=0.984)$ (Fig.7).

In vivo study:

In human subjects, TMR measured with the PDM $(0.34 \pm 0.10 \mathrm{~mm})$ and VM

$(0.36 \pm 0.11 \mathrm{~mm})$ was significantly correlated $(r=0.940 ; p<0.001)$. The mean difference between PDM and VM was $-0.0151 \mathrm{~mm}(\mathrm{Cl}-0.0285$ to $-0.0018 \mathrm{~mm} ; \mathrm{p}=0.124)$ in this cohort (Fig.8).

\section{Discussion}

Reflective meniscometry is a non-invasive method to measure TMR, useful in dry eye diagnosis. The first photographic meniscometer was introduced by Bron in 1997 and Yokoi et al. in 1999., 26 It consists of a target of 14 black and 13 white lines, each $2 \mathrm{~mm}$ wide, attached to a macro-camera. ${ }^{1} \mathrm{~A}$ video system with a CCD camera and target consisting of a central white bar of $3.5 \mathrm{~mm}$ wide on a black surround was also described. A modification of the video system called "video-meniscometer" with a target of a series of black metal bars, $4 \mathrm{~mm}$ wide and $4 \mathrm{~mm}$ apart, set directly in front of the objective lens and illuminated from behind was developed by Oguz et al. ${ }^{24}$ and Yokoi et al. ${ }^{21}$ in 2000 . In a similar manner to this study, calibration for the original meniscometer system was carried out using glass capillaries. ${ }^{1}$ Also using glass capillaries Kato et al. found no significant differences between TMR measured with the VM and an anterior segment optical coherence tomographer. ${ }^{27}$ 
125 With our new developed ipod-touch based portable, slit-lamp mounted meniscometer

126 we found a good accuracy and reproducibility across the whole range of typical TMR

127 (Figure 6). In contrast the VM seems to have the tendency to under-estimate the

128 TMR for small radii and to over-estimate TMR for larger radii (Figure 7).

130 This effect also becomes obvious in the comparison between the two methods

131 (Figure 7). So the radii measured by the PDM seem to be more consistent than those measured by the VM. These differences might be caused by the different design of the target lines. While the VM uses metal bars mounted directly in front of the observation system, the target of the PDM consists of digital produced lines which are separated from the observation system. As a result, the PDM target does not 136 interfere with the observation system of the slit-lamp, since the VM target effectively

137 functions as an aperture within the observation system thus influencing the depth of field. A second source of error arises from the working distance of the instrument. While the VM has a working distance of $24 \mathrm{~mm}$, a longer distance of $50 \mathrm{~mm}$ is used

140 by the PDM. By looking at the concave mirror formula (Figure 3) it becomes obvious 141 that the smaller the working distance (a) is the greater the error gets if the system is 142 not exactly aligned.

144 With the PDM we found a TMR of $(0.34 \pm 0.10 \mathrm{~mm})$ in a group of normal non-dry eye 145 patients. This was not significantly different from the TMR measured with the VM $146(0.36 \pm 0.11 \mathrm{~mm})$ and is in accordance to previously reported measurements with 147 reflective meniscometry in normal. ${ }^{1,21}$ The correlation between the two methods 148 indicates the PDM is a valid measure of TMR. For dry eye patients the reported TMR 149 measured with reflective meniscometry varies between 0.22 and $0.25 \mathrm{~mm}$. 21,24

150 While meniscometry uses specular reflexion to analyse TMR, in optical coherence 
151

152

153

154

tomography a vertical line scan produces a cross-sectional image of the tear meniscus. On the images taken with an OCT, the 3-point method is used to fit a circle to the anterior border of tear meniscus. TMR of the lower tear meniscus reported with this method varies from 0.25 to $0.46 \mathrm{~mm}$ for normals and between 0.15 to $0.20 \mathrm{~mm}$ in dry eye patients. ${ }^{15,17,18,20,28}$

For the purpose of calculating meniscus volume, the anterior shape of the meniscus is treated as a part of a circle even it is likely to have a more complex shape. ${ }^{29}$ To understand differences in TMR measurements between reflective meniscometry and optical coherence tomography it would be helpful to describe the shape of the meniscus more precisely and to analyse the location on the meniscus were the PDM is measuring the meniscus. While OCT and the existing VM have a fixed vertical orientation of the target, the PDM allows a rotation of the target and therefore a measurement of the meniscus under different angles. Furthermore the line width of the target can be easily varied via the touch screen. This enables the projection of different grids to the meniscus, which may help give a more detailed description of tear meniscus anterior shape.

In the literature the measurement of tear meniscus parameters is mostly performed at the centre of the lower eyelid, directly under the pupil. Some authors report tear meniscus height $(\mathrm{TMH})$ to be greater at the centre of the lid, ${ }^{30}$ but others find no thinning of the inferior tear meniscus, ${ }^{31}$ or even that the TMH that is smaller at the center. ${ }^{11}$ These differences might be explained by the different techniques used and the different locations at which TMH was measured. At the same time, when calculating tear meniscus volume, the meniscus is assumed to be equal along the lower lid, ${ }^{5,32}$ or a correction factor of $3 / 4$ is used to account for an unequal 
177 distribution. ${ }^{30,33,34}$ Since the PDM is mounted on a standard slit-lamp it can be used

178 for measurement of $\mathrm{TMH}$ and at the same time for measurement of TMR at different

179 location along the lid and therefore to analyse tear film distribution along the lid.

180

181 Conclusions:

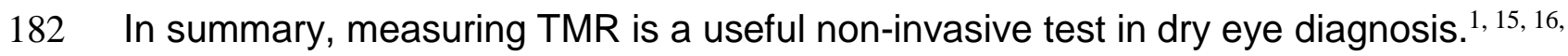

$183{ }^{20,21}$ The potential techniques to measure TMR are either not commercially available

184 or too expensive for clinical use. We have developed a portable, slit-lamp mounted,

185 digital meniscometer that produces accurate and reliable measurements, and is able

186 to provide similar values for tear meniscus radius, in human studies, to the existing

187 video-meniscometer. This makes the instrument suitable for use in both research and 188 clinical practice.

189

190

191

192

193

194

195

196

197

198

199

200 


\section{References}

202 1. Yokoi N, Bron A, Tiffany J, Brown N, Hsuan J, Fowler C. Reflective 203 meniscometry: a non-invasive method to measure tear meniscus curvature. $\mathrm{Br} \mathrm{J}$ 204 Ophthalmol 1999;83:92-7.

2052 The definition and classification of dry eye disease: report of the Definition and 206 Classification Subcommittee of the International Dry Eye WorkShop (2007). Ocul 207 Surf 2007;5:75-92.

208 3. Holly FJ. Physical chemistry of the normal and disordered tear film. Trans 209 Ophthalmol Soc U K 1985;104 ( Pt 4):374-80.

210 4. Mainstone JC, Bruce AS, Golding TR. Tear meniscus measurement in the 211 diagnosis of dry eye. Curr Eye Res 1996;15:653-61.

212 5. Palakuru JR, Wang J, Aquavella JV. Effect of blinking on tear dynamics. Invest 213 Ophthalmol Vis Sci 2007;48:3032-7.

214 6. Yokoi N, Bron AJ, Tiffany JM, Maruyama K, Komuro A, Kinoshita S.

215 Relationship between tear volume and tear meniscus curvature. Arch Ophthalmol $216 \quad 2004 ; 122: 1265-9$.

217 7. Scherz W, Doane MG, Dohlman $\mathrm{CH}$. Tear volume in normal eyes and 218 keratoconjunctivitis sicca. Albrecht Von Graefes Arch Klin Exp Ophthalmol 219 1974;192:141-50.

220 8. Lamberts DW, Foster CS, Perry HD. Schirmer test after topical anesthesia and 221 the tear meniscus height in normal eyes. Arch Ophthalmol 1979;97:1082-5.

222 9. Miller WL, Doughty MJ, Narayanan S, Leach NE, Tran A, Gaume AL, 223 Bergmanson JP. A comparison of tear volume (by tear meniscus height and phenol 224 red thread test) and tear fluid osmolality measures in non-lens wearers and in contact 225 lens wearers. Eye Contact Lens 2004;30:132-7. 
226 10. Nichols KK, Mitchell GL, Zadnik K. The repeatability of clinical measurements 227 of dry eye. Cornea 2004;23:272-85.

228 11. Garcia-Resua C, Santodomingo-Rubido J, Lira M, Giraldez MJ, Vilar EY.

229 Clinical assessment of the lower tear meniscus height. Ophthalmic Physiol Opt 2009.

230 12. Santodomingo-Rubido J, Wolffsohn JS, Gilmartin B. Comparison between 231 graticule and image capture assessment of lower tear film meniscus height. Cont 232 Lens Anterior Eye 2006;29:169-73.

233 13. Johnson ME, Murphy PJ. The agreement and repeatability of tear meniscus 234 height measurement methods. Optom Vis Sci 2005;82:1030-7.

235 14. Yokoi N, Komuro A. Non-invasive methods of assessing the tear film. Exp Eye 236 Res 2004;78:399-407.

237 15. Shen M, Li J, Wang J, Ma H, Cai C, Tao A, Yuan Y, Lu F. Upper and lower 238 tear menisci in the diagnosis of dry eye. Invest Ophthalmol Vis Sci 2009.

239 16. Bron AJ, Yokoi N, Tiffany JM, Brown NAP, Fowler CW. The clinical value of 240 reflective meniscometry in dry eye diagnosis. Invest Ophthalmol Vis Sci 1998;39:65.

241 17. Wang J, Palakuru JR, Aquavella JV. Correlations among upper and lower tear 242 menisci, noninvasive tear break-up time, and the Schirmer test. Am J Ophthalmol $243 \quad 2008 ; 145: 795-800$.

244 18. Wang J, Aquavella J, Palakuru J, Chung S, Feng C. Relationships between 245 central tear film thickness and tear menisci of the upper and lower eyelids. Invest 246 Ophthalmol Vis Sci 2006;47:4349-55.

247 19. Wang J, Cox I, Reindel WT. Upper and lower tear menisci on contact lenses. 248 Invest Ophthalmol Vis Sci 2008.

249 20. Li J, Shen M, Wang J, Ma H, Tao A, Xu S, Lu F. Clinical significance of tear 250 menisci in dry eye. Eye Contact Lens 2012;38:183-7. 
251 21. Yokoi N, Bron AJ, Tiffany JM, Kinoshita S. Reflective meniscometry: a new

252 field of dry eye assessment. Cornea 2000;19:S37-43.

253 22. Yokoi N, Komuro A, Maruyama K, Kinoshita S. New instruments for dry eye 254 diagnosis. Semin Ophthalmol 2005;20:63-70.

25523. Oguz $\mathrm{H}$. Noninvasive tear meniscometry in dry eye patients with Sjogren 256 syndrome. Am J Ophthalmol 2008;145:184; author reply -5.

257 24. Oguz H, Yokoi N, Kinoshita S. The height and radius of the tear meniscus and 258 methods for examining these parameters. Cornea 2000;19:497-500.

259 25. Savini G, Prabhawasat P, Kojima T, Grueterich M, Espana E, Goto E. The 260 challenge of dry eye diagnosis. Clin Ophthalmol 2008;2:31-55.

261 26. Bron AJ. The Doyne Lecture. Reflections on the tears. Eye (Lond) 1997;11 ( 262 Pt 5):583-602.

263 27. Kato H, Yokoi N, Bron AJ, Tiffany JM, Kinoshita S. Meniscometry using 264 anterior segment optical coherence tomography. In: 6th International Conference on 265 the Tear Film \& Ocular Surface. Florence, Italy; 2010.

266 28. Palakuru JR, Wang J, Aquavella JV. Effect of blinking on tear volume after 267 instillation of midviscosity artificial tears. Am J Ophthalmol 2008;146:920-4.

268 29. Bron AJ, Yokoi N, Gaffney EA, Tiffany JM. A solute gradient in the tear 269 meniscus. I. A hypothesis to explain Marx's line. Ocul Surf 2011;9:70-91.

27030 . Jones LW, Rahman S, Leech R, Simpson T, Fonn D. Determination of Inferior 271 Tear Meniscus Height and Inferior Tear Meniscus Volume Using Optical Coherence 272 Tomography In: Invest Ophthalmol Vis Sci 2004. p. E-Abstract 144.

273 31. Harrison WW, Begley CG, Liu H, Chen M, Garcia M, Smith JA. Menisci and 274 fullness of the blink in dry eye. Optom Vis Sci 2008;85:706-14.

275 32. Tiffany JM, Todd BS, Baker MR. Computer-assisted calculation of exposed 276 area of the human eye. Adv Exp Med Biol 1998;438:433-9. 
277 33. Wang J, Simmons P, Aquavella J, Vehige J, Palakuru J, Chung S, Feng C.

278 Dynamic distribution of artificial tears on the ocular surface. Arch Ophthalmol $279 \quad 2008 ; 126: 619-25$.

280 34. Chen Q, Wang J, Shen M, Cai C, Li J, Cui L, Qu J, Lu F. Lower volumes of 281 tear menisci are associated with dry eye symptoms in contact lens wearers. Invest 282 Ophthalmol Vis Sci 2009.

283

284

285

286

287

288

289

290

291

292

293

294

295

296

297

298

299

300

301 
Figures:

304

305 Figure 1. iPod-touch (Apple Inc., Cupertino, CA, USA) as a target with adjustable 306 grid width. The numbers on the touch screen give the width of the bars in $\mathrm{mm}$ and 307 the vertical orientation of the instrument in degrees.

308

309

Figure 2. PDM instrument mounted on a digital imaging slit-lamp (BQ900 with IM900 digital imaging module, Haag-Streit, Koeniz, Switzerland).

Figure 3. Measurement of line distance on the PDM-image using ImageJ 1.46

313 software.

314

Figure 4. Concave mirror formula for calculation of the tear meniscus radius in reflective meniscometry.

Figure 5. Video-meniscometer.

Figure 6. In vitro radius difference between sessions of the PDM.

Figure 7. In vitro radius difference between sessions of the VM.

Figure 8. In vitro radius difference between PDM and VM.

Figure 9. In vivo radius difference between PDM and VM. 
328 Figure 10a. Example of a steep tear meniscus radius $(\mathrm{r}=0.19 \mathrm{~mm})$ measured with 329 the PDM.

330

331 Figure 10b. Example of a flat tear meniscus radius $(r=0.42 \mathrm{~mm})$ measured with the 332 PDM. 
Figure 1

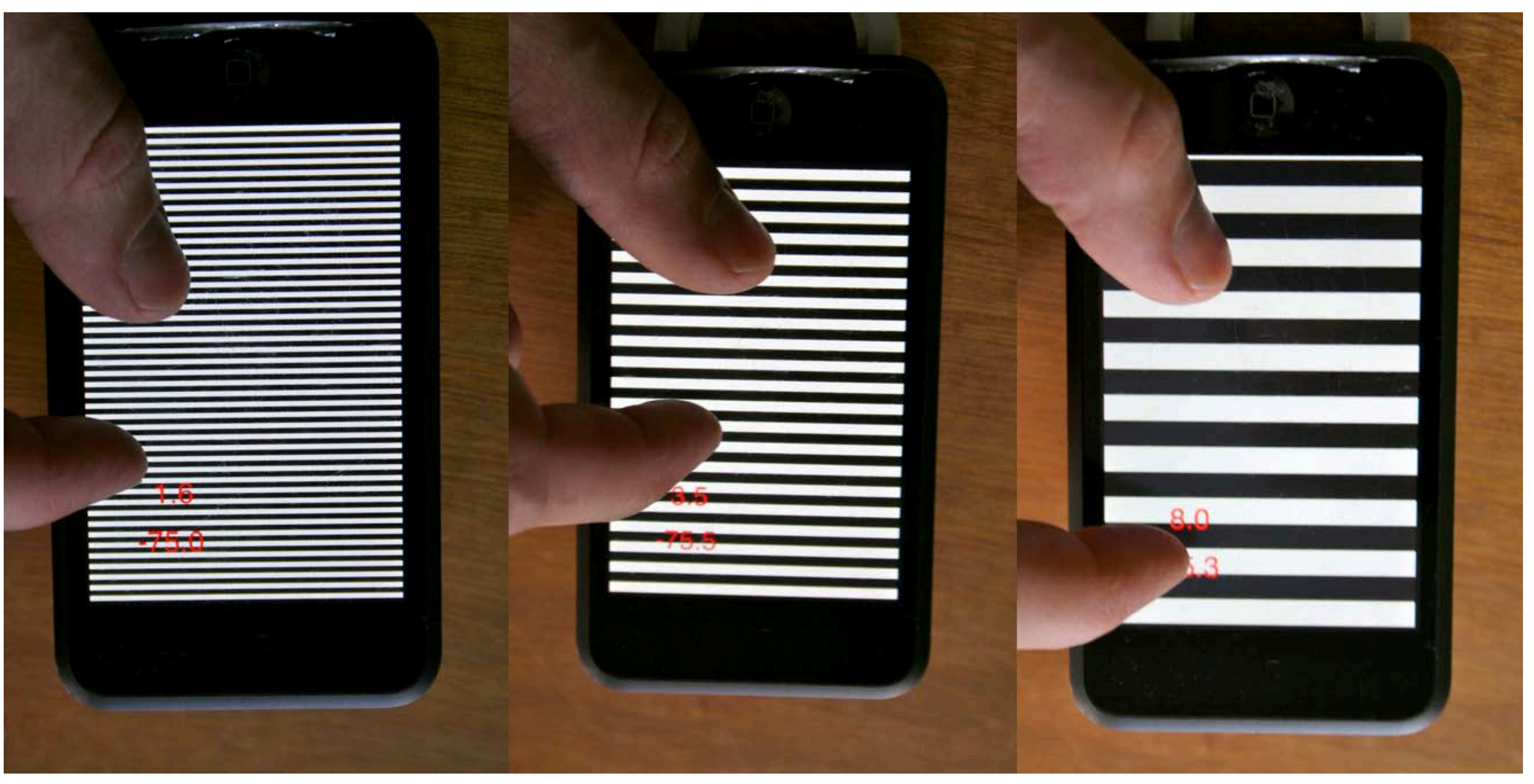


Figure 2

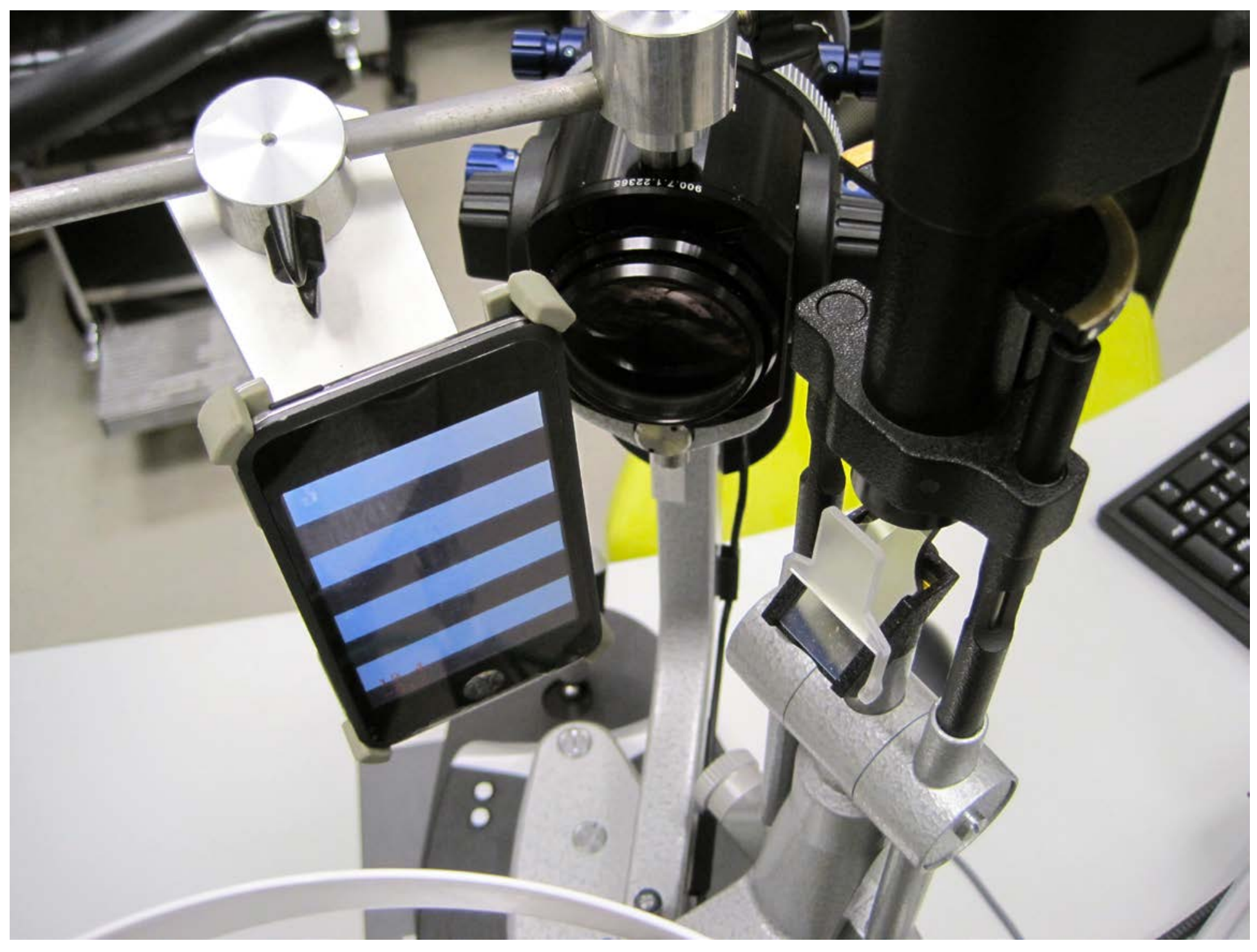


Figure 3

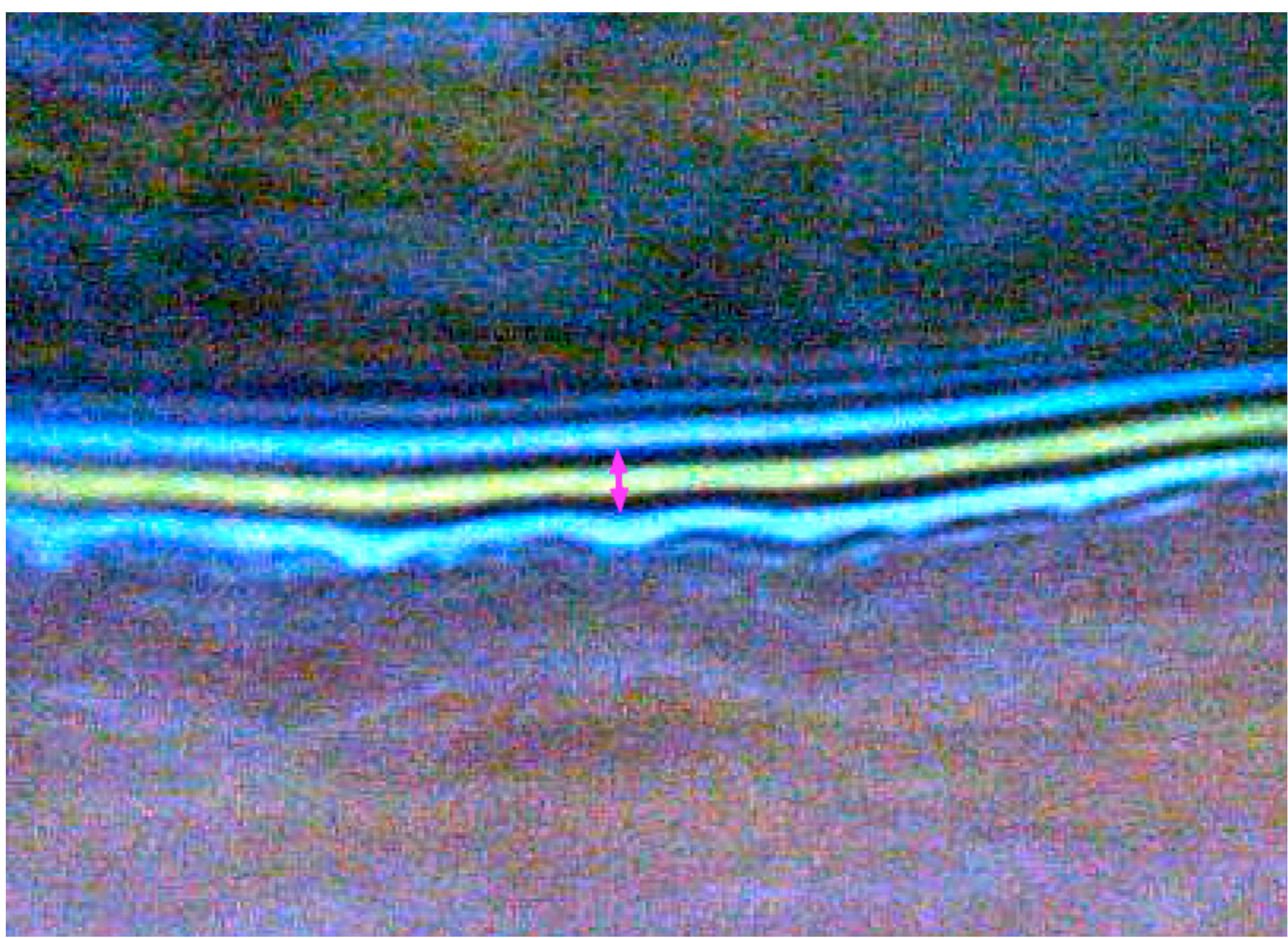


Figure 4

\begin{tabular}{|l|l|}
\hline$r=\frac{2 \cdot a \cdot y^{\prime}}{y-y^{\prime}}$ & $\begin{array}{l}\mathrm{r}=\text { radius of meniscus curvature } \\
\mathrm{a}=\text { target distance } \\
\mathrm{y}=\text { target size } \\
\mathrm{y}^{\prime}=\text { image size }\end{array}$ \\
\hline
\end{tabular}


Figure 5

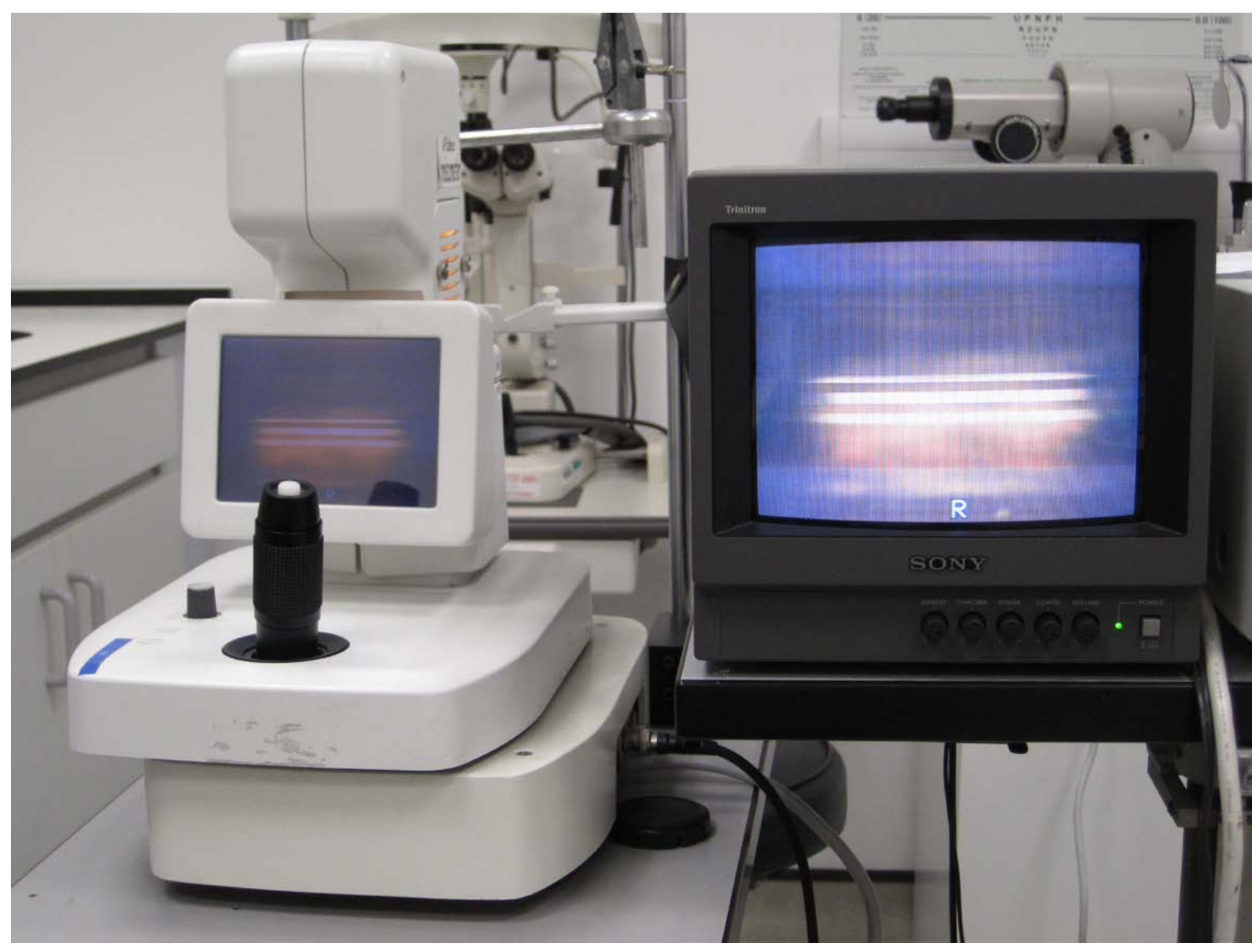


Figure 6

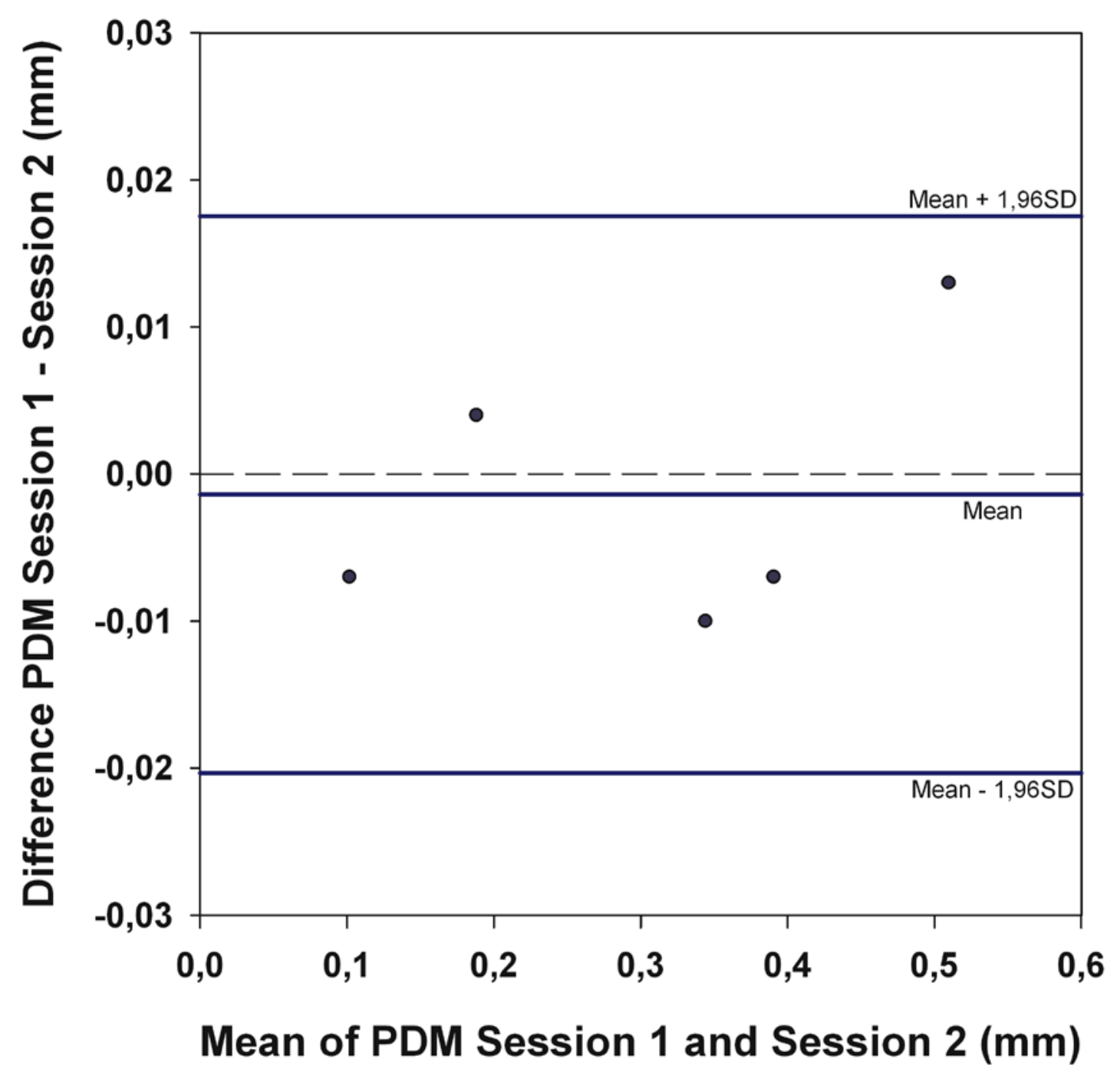


Figure 7

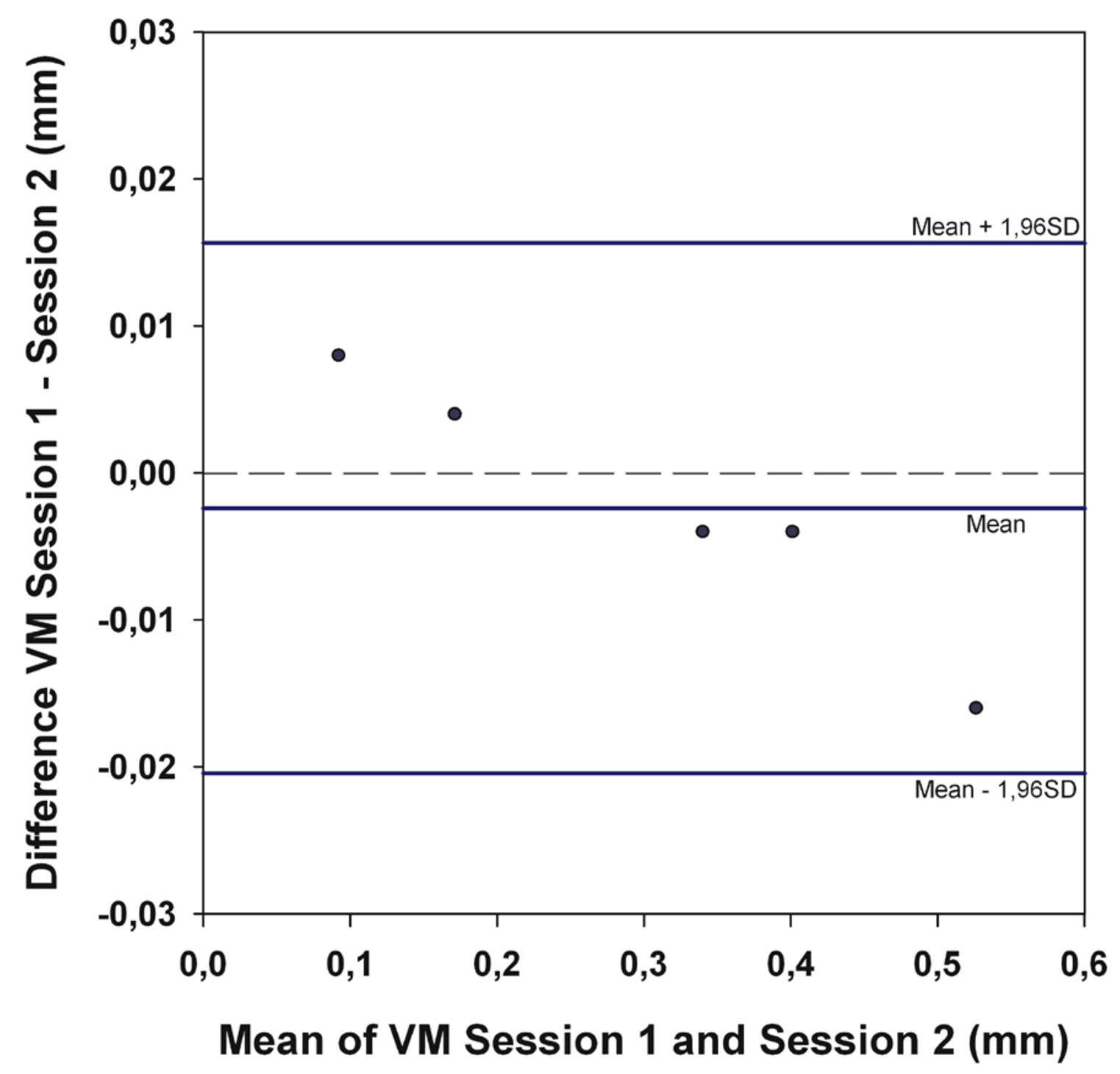


Figure 8

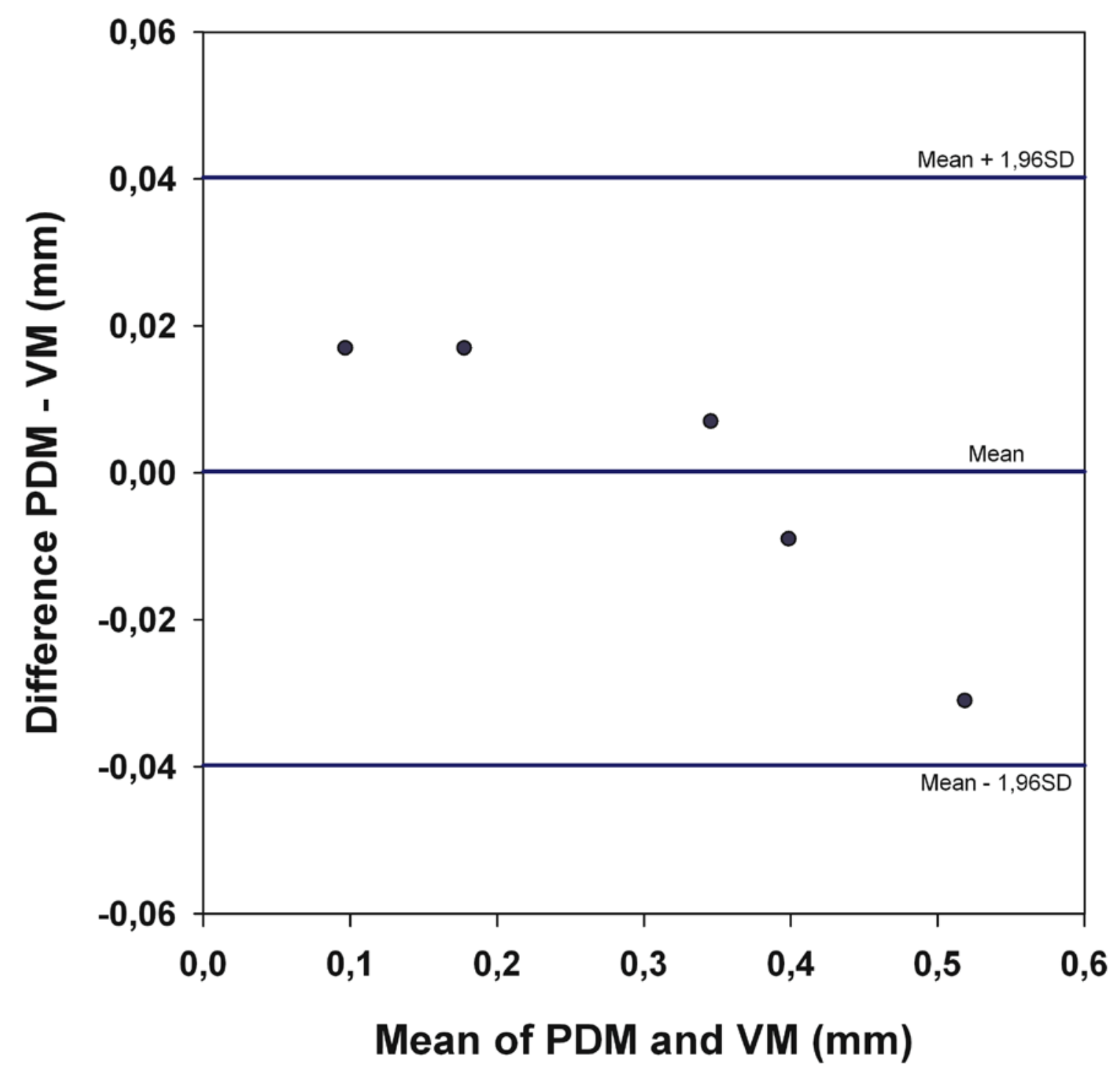


Figure 9

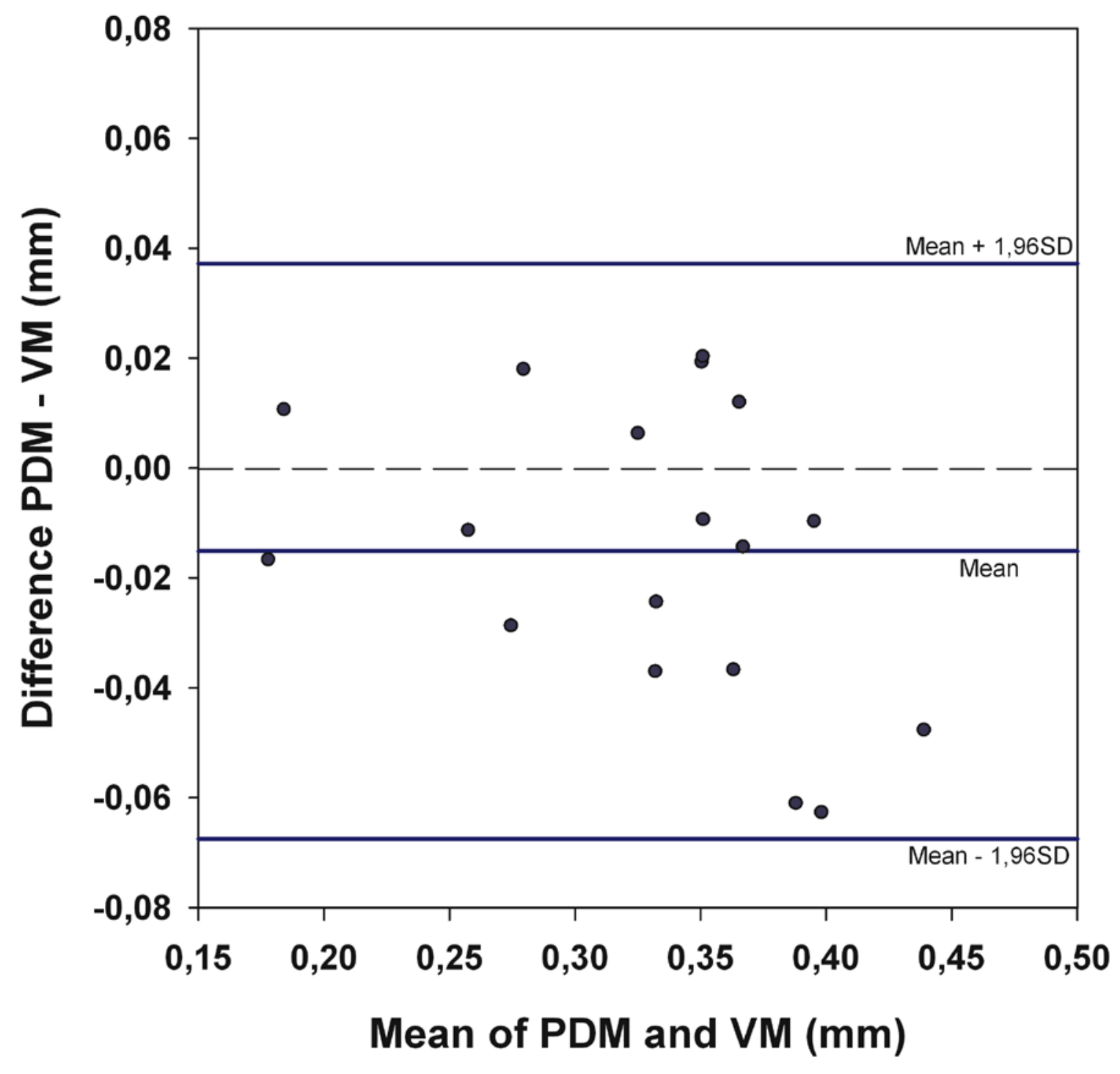


Figure 10a

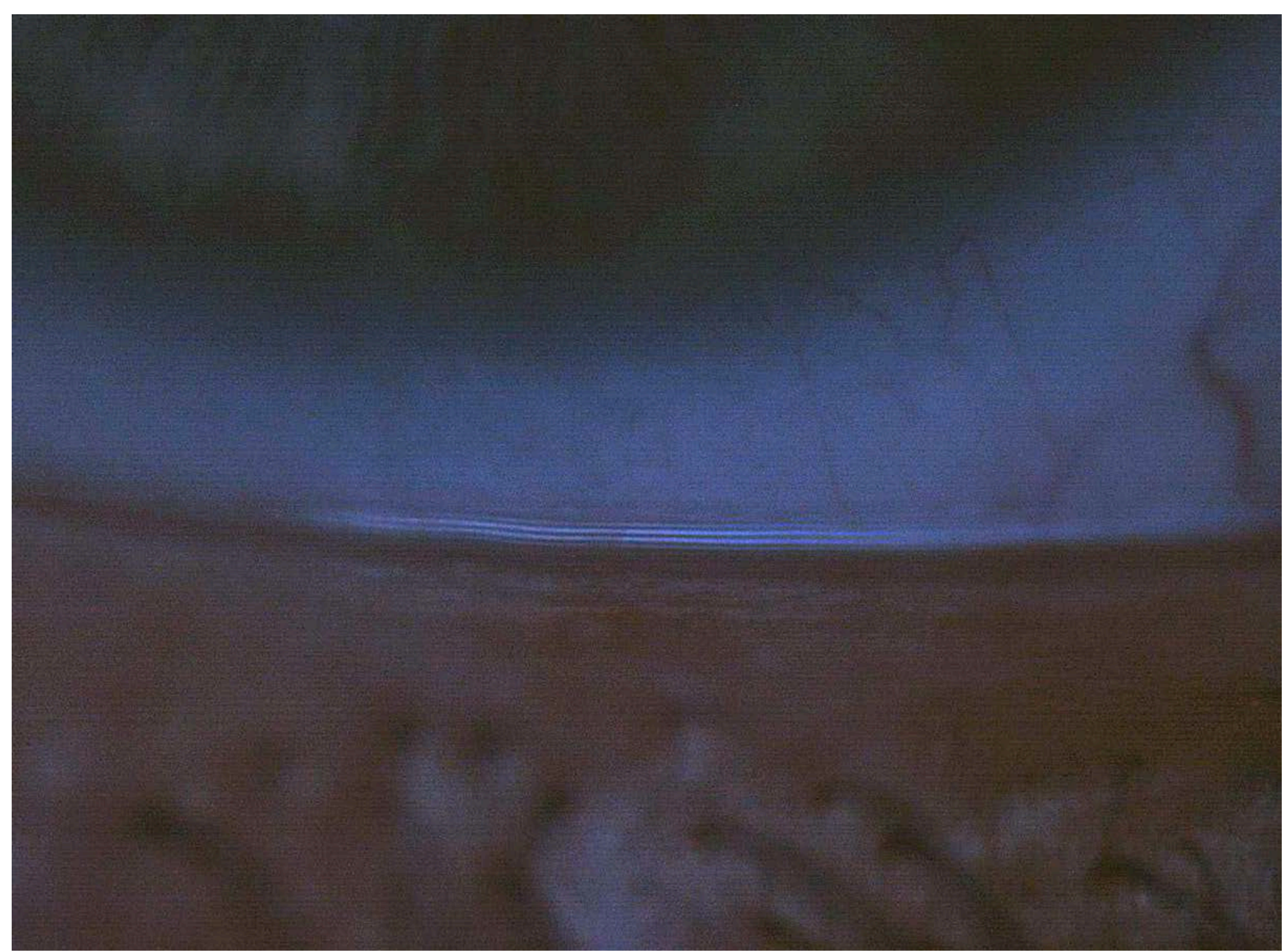


Figure 10b

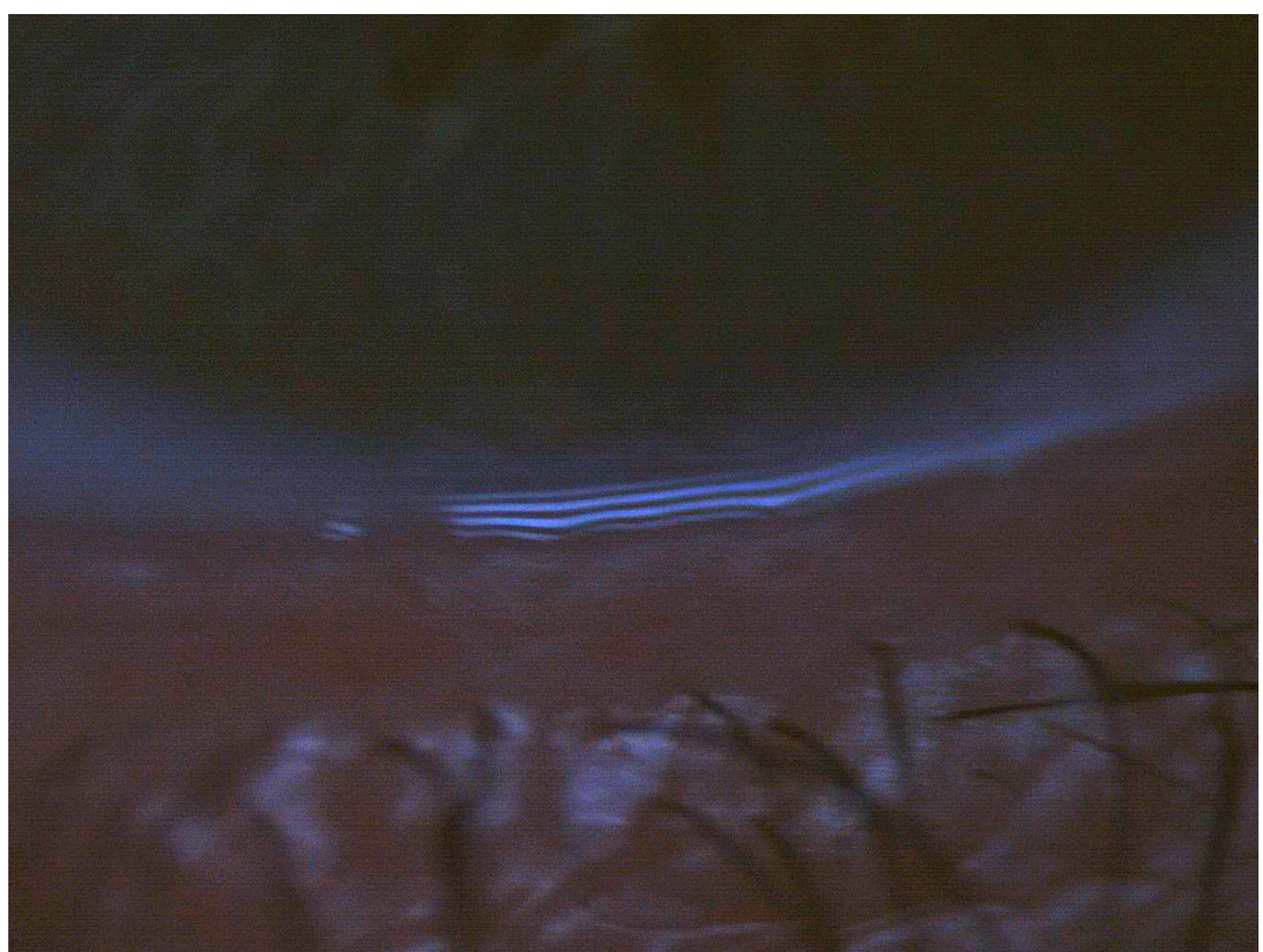

